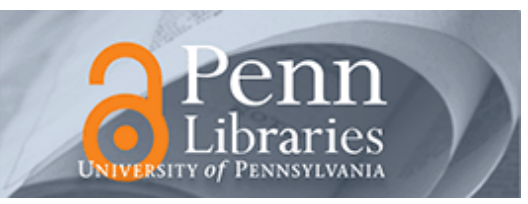

University of Pennsylvania

ScholarlyCommons

August 2006

\title{
Induction of osteoblast differentiation markers in human dermal fibroblasts: potential application to bone tissue engineering.
}

Christopher K. Hee

University of Pennsylvania

Steven B. Nicoll

University of Pennsylvania, nicoll@seas.upenn.edu

Follow this and additional works at: https://repository.upenn.edu/be_papers

\section{Recommended Citation}

Hee, C. K., \& Nicoll, S. B. (2006). Induction of osteoblast differentiation markers in human dermal fibroblasts: potential application to bone tissue engineering.. Retrieved from https://repository.upenn.edu/ be_papers/106

Copyright 2006 IEEE. Reprinted from Proceedings of the 28th IEEE Engineering in Medicine and Biology Science Annual International Conference, (EMBS 2006), August 2006, 4 pages.

This material is posted here with permission of the IEEE. Such permission of the IEEE does not in any way imply IEEE endorsement of any of the University of Pennsylvania's products or services. Internal or personal use of this material is permitted. However, permission to reprint/republish this material for advertising or promotional purposes or for creating new collective works for resale or redistribution must be obtained from the IEEE by writing to pubs-permissions@ieee.org. By choosing to view this document, you agree to all provisions of the copyright laws protecting it.

This paper is posted at ScholarlyCommons. https://repository.upenn.edu/be_papers/106

For more information, please contact repository@pobox.upenn.edu. 


\title{
Induction of osteoblast differentiation markers in human dermal fibroblasts: potential application to bone tissue engineering.
}

\author{
Abstract \\ Tissue engineered constructs have the potential to be used as replacements for current bone graft \\ technologies. One component necessary for bone tissue engineering is a readily available, osteogenic cell \\ source. Human dermal fibroblasts may have the potential to differentiate along an osteoblastic lineage, \\ making them a candidate for use in bone tissue engineering applications. The objective of this study was \\ to validate the ability of dermal fibroblasts to express gene and protein markers of osteoblastic \\ differentiation and to explore their potential, in combination with biomaterial scaffolds and signaling \\ factors, for use in bone tissue engineering.

\section{Comments} \\ Copyright 2006 IEEE. Reprinted from Proceedings of the 28th IEEE Engineering in Medicine and Biology \\ Science Annual International Conference, (EMBS 2006), August 2006, 4 pages. \\ This material is posted here with permission of the IEEE. Such permission of the IEEE does not in any way \\ imply IEEE endorsement of any of the University of Pennsylvania's products or services. Internal or \\ personal use of this material is permitted. However, permission to reprint/republish this material for \\ advertising or promotional purposes or for creating new collective works for resale or redistribution must \\ be obtained from the IEEE by writing to pubs-permissions@ieee.org. By choosing to view this document, \\ you agree to all provisions of the copyright laws protecting it.
}




\title{
Induction of Osteoblast Differentiation Markers in Human Dermal Fibroblasts: Potential Application to Bone Tissue Engineering
}

\author{
Christopher K. Hee and Steven B. Nicoll
}

\begin{abstract}
Tissue engineered constructs have the potential to be used as replacements for current bone graft technologies. One component necessary for bone tissue engineering is a readily available, osteogenic cell source. Human dermal fibroblasts may have the potential to differentiate along an osteoblastic lineage, making them a candidate for use in bone tissue engineering applications. The objective of this study was to validate the ability of dermal fibroblasts to express gene and protein markers of osteoblastic differentiation and to explore their potential, in combination with biomaterial scaffolds and signaling factors, for use in bone tissue engineering.
\end{abstract}

\section{INTRODUCTION}

$\mathrm{T}_{\mathrm{p}}^{\mathrm{p}}$ HERE are over 600,000 bone graft procedures performed in the United States each year[1]. Autografts are used in approximately 90 percent of these surgeries, with natural and synthetic scaffolds accounting for the remaining 10 percent[2]. While these methods are suitable for use in bone graft procedures, there are inherent limitations to their use, including limited supply, disease transmission, and inferior mechanical and biological properties.

Bone tissue engineering using a combination of an osteogenic cell source, a biomaterial scaffold, and growth factors has the potential as a replacement for current graft materials[3]. Native osteoblasts are typically difficult to isolate and expand in vitro, which makes them less than ideal for bone tissue engineering applications[4]. One potential alternative source of cells that is nonimmunogenic, easily expandable, and readily available through a minimally invasive harvesting procedure are dermal fibroblasts. Osteoinduction was first described by Marshall Urist as the ability of demineralized bone matrix to induce the osteoblastic differentiation of host fibroblasts [5]. Additionally the potential of fibroblasts to differentiate towards an osteoblastic lineage have been investigated[6$11]$.

The objective of the following studies was to investigate the potential of human dermal fibroblasts, in combination with $1 \alpha, 25$-dihydroxyvitamin $\mathrm{D}_{3}$, as a source of cells for bone tissue engineering applications.

Manuscript received May 15, 2006. This work was supported in part by the Whitaker Foundation.

Christopher K. Hee is with the Department of Bioengineering, University of Pennsylvania, Philadelphia, PA 19104 USA.

Steven B. Nicoll is with the Department of Bioengineering and the Department of Orthopaedic Surgery, University of Pennsylvania, Philadelphia, PA 19104 USA.

\section{MATERIALS AND METHODS}

\section{A. Cell Culture}

Neonatal human dermal fibroblasts (Cascade Biologics, Portland, OR) were maintained in basal medium consisting of minimum essential medium (MEM) containing $10 \%$ fetal bovine serum (FBS), $100 \mathrm{U} / \mathrm{ml}$ penicillin, $100 \mu \mathrm{g} / \mathrm{ml}$ streptomycin, and $0.075 \%$ sodium bicarbonate and incubated at $37^{\circ} \mathrm{C}$ with $5 \% \mathrm{CO}_{2}$.

1) Vitamin D Dose Dependence: Neonatal fibroblasts were plated at a density of 4500 cells $/ \mathrm{cm}^{2}$ in $100-\mathrm{mm}$ dishes in basal medium containing $1,10,100$, and $1000 \mathrm{nM} 1 \alpha, 25-$ dihydroxyvitamin $D_{3}$ (vitamin $\quad D$ ) with $10 \mathrm{mM} \quad \beta$ glycerophosphate $(\beta \mathrm{GP})$ and $50 \mu \mathrm{g} / \mathrm{ml}$ L-ascorbic acid. DMSO $(0.02 \%)$ was added as a vehicle control. Alkaline phosphatase activity was quantified at 14 days. All further studies used $100 \mathrm{nM}$ vitamin D.

2) Monolayer Culture: Neonatal fibroblasts were trypsinized and plated on $100 \mathrm{~mm}$ dishes at a seeding density of $4500 \mathrm{cell} / \mathrm{cm}^{2}$ in basal serum-containing medium (S medium). Experimental cultures were plated in basal medium containing $100 \mathrm{nM}$ vitamin $\mathrm{D}, 10 \mathrm{mM} \beta \mathrm{GP}$, and 50 $\mu \mathrm{g} / \mathrm{ml}$ L-ascorbic acid (S+vitD medium). After 24 hours, all cultures were rinsed thoroughly with phosphate buffered saline (PBS) and the medium was replaced with chemicallydefined medium in which 1\% insulin-transferrin-selenium (ITS) was substituted for serum (I and I+vitD medium). Fibroblast controls were maintained in $\mathbf{S}$ and $\mathbf{S}+$ vitD medium. Samples were analyzed at 7, 14, and 21 days for gene expression, biochemistry, and histology.

3) Bone Morphogenetic Protein (BMP) Signaling: Cells were plated at a cell density of 10,000 cells $/ \mathrm{ml}$ in 24 well plates in $\mathbf{S}$ or $\mathbf{S}+$ vitD medium. The recombinant BMP antagonist, noggin (R\&D Systems, Minneapolis, MN), was added at a concentration of $0.1 \mu \mathrm{g} / \mathrm{ml}$ to additional cultures maintained in $\mathbf{S}+$ vitD medium. After 24 hours, cultures were rinsed with PBS and experimental cultures were maintained in I+vitD medium with or without $0.1 \mu \mathrm{g} / \mathrm{ml}$ Noggin. Control cultures were maintained in $\mathbf{S}$ medium. At 3 and 14 days, samples were taken for analysis of gene expression and biochemistry.

4) Three-Dimensional Culture Seeding Density: Dermal fibroblasts were seeded on 9-mm diameter, 3-mm thick ultraporous $\beta$-tricalcium phosphate ( $\beta$ TCP) scaffolds (Vitoss, Orthovita, Malvern, PA) at densities of 0.5, 1.5, 3.0, and 5.0 million cells/scaffold in $70 \mu \mathrm{l}$ of $\mathbf{S}$ medium. Cells 
were allowed to attach for 20 minutes and then flooded with either $\mathbf{S}$ or $\mathbf{S}+$ vitD medium. After 24 hours, scaffolds were rinsed with PBS and maintained in $\mathbf{S}, \mathbf{S}+\mathbf{v i t D}, \mathbf{I}$, or I+vitD medium. Constructs were analyzed at $7,14,21$, and 28 days for gene expression, biochemistry, and histology and immunochemistry.

\section{B. Gene Expression}

Total cellular RNA was extracted using the TRIzol isolation system (Invitrogen). Reverse transcription was performed using the Superscript First-Strand synthesis system for RT-PCR. Polymerase chain reactions for the monolayer study were carried out using TAQ DNA polymerase and oligonucleotide primers for human alkaline phosphatase[12], osteocalcin, osteopontin [11], and $\beta$ Actin[13]. PCR products were resolved on a $1 \%$ agarose gel and analyzed by densitometry using Scion Image (Scion Corporation, Frederick, MD). Real-time PCR was performed in the BMP signaling and three-dimensional density dependence studies. Primers for alkaline phosphatase were as published[14]. Osteocalcin primers and probes were purchased as a TAQMAN gene expression assay (Hs01587813 g1, Applied Biosystems) and BMP6 and GAPDH primers and probes were designed with Primer Express 3.0 software (Applied Biosystems). Real-time PCR reactions were performed with SYBR Green Master Mix or TAQMAN Master Mix (Applied Biosystems) using an Applied Biosystems 7300 real-time PCR system. Relative gene expression was determined using the $\Delta \Delta \mathrm{C}_{\mathrm{t}}$ method (Applied Biosystems User Bulletin \#2).

\section{Biochemistry}

Protein and DNA were extracted with a $0.5 \%$ Triton-X 100 in PBS. Samples cultured on $\beta$-TCP scaffolds required further extraction of DNA using $0.48 \mathrm{M}$ sodium phosphate. Alkaline phosphatase activity was determined using a colorimetric assay (Sigma) in which p-nitrophenyl phosphate is cleaved to p-nitrophenol. The absorbance of the resulting product was read at $400 \mathrm{~nm}$ on a Biotek Synergy HT multidetection reader.

Total DNA content was measured using the PicoGreen double-stranded DNA assay adapted for use in a microplate reader[15].

\section{Histology and Immunohistochemistry}

Samples were fixed with $10 \%$ neutral buffered formalin or $4 \%$ paraformaldehyde. Three-dimensional scaffolds were dehydrated and embedded in paraffin. Serial $7-\mu \mathrm{m}$ thick sections were processed for histological and Immunohistochemical analysis. Active alkaline phosphatase was localized by staining for 30 minutes with a Fast Blue RR-salt and Naphthol AS-MX phosphate dye (Sigma). Alexa Fluor 488-conjugated phalloidin (Molecular Probes) at a concentration of 5 units $/ \mathrm{ml}$ was used to stain F-actin.

Polyclonal antibodies for osteocalcin (V-19, Santa Cruz Biotechnology, Santa Cruz, CA) were used with a peroxidase-based detection system (Vectastain Elite $A B C$, Vector Labs, Burlingame, $\mathrm{CA}$ ) and 3,3' diaminobenzidine as the substrate chromagen to detect protein localization. Nonimmune controls were performed without primary antibody.

\section{E. Statistical Analysis}

All data are presented as the mean \pm standard deviation. One- (vitamin D dose dependence), two-(monolayer and noggin studies), or three-way (density dependence study) ANOVAs with Tukey post-hoc tests were used to determine the effect of vitamin D dose dependence, culture medium, culture duration, and seeding density. Significance was set at $\mathrm{p}<0.05$.

\section{REsUlts}

1) Vitamin D Dose-Dependence: Expression of alkaline phosphatase activity normalized to DNA content showed a dose-dependent response to vitamin D. Significant increases in activity were observed when cells were cultured in the presence of 10 and $100 \mathrm{nM}$ vitamin $\mathrm{D}$, with maximal activity at $100 \mathrm{nM}$. Additionally, an increase in vitamin $\mathrm{D}$ to $1000 \mathrm{nM}$ resulted in a decrease in activity to a level similar to DMSO controls.
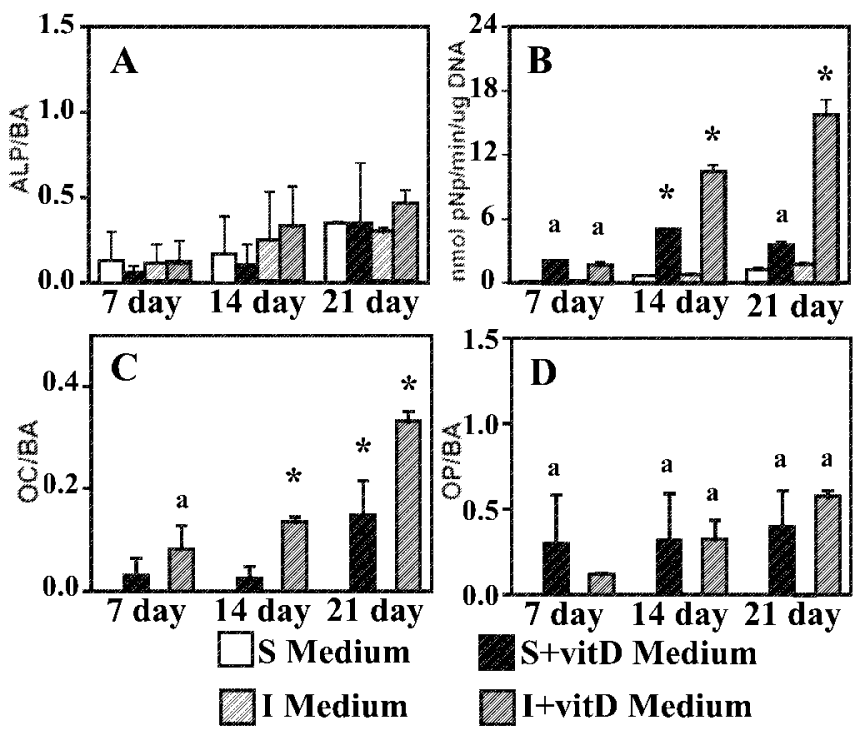

Fig. 1: Ostcoblast-specific gene expression by human dermal fibroblast cultures. Cells were cultured in S, S+vitD, I, or I+vitD medium. (A) Alkaline phosphatase, (C) osteocalcin, and (D) osteopontin gene expression were normalized to $\beta$-Actin. (B) Alkaline phosphatase activity was normalized to DNA content. (a: $\mathrm{p}<0.05$ compared to $\mathrm{S}$, I cultures, *: $\mathrm{p}<0.05$ compared to all culture conditions)

2) Monolayer Culture: Human dermal fibroblasts plated in monolayer were analyzed at 7, 14, and 21 day time points for gene expression, biochemistry, and histology. Alkaline phosphatase, osteopontin, and osteocalcin were analyzed as markers of osteoblastic gene expression. Alkaline phosphatase (Fig 1A) was detected in all cultures with a significant up-regulation observed over time. There was no significant effect of culture medium on alkaline phosphatase expression. Osteocalcin (Fig 1C) was only observed in cultures containing vitamin $\mathrm{D}$, with a significant effect of both culture duration and culture medium. Osteocalcin expression was highest in cultures maintained in serum-free 
medium with vitamin $D$, with maximum expression at 21 days. Similar to osteocalcin, osteopontin (Fig 1D) was only observed in cultures supplemented with vitamin D. Maximal osteopontin expression was seen at 21 days.

Alkaline phosphatase activity normalized to DNA content (Fig 1B) was elevated in monolayer cultures containing vitamin $\mathrm{D}$ at both 14 and 21 days. This increase was significantly greater in serum-free cultures compared to those containing serum. Alkaline phosphatase staining was observed in all cultures, with the highest levels of staining detected in fibroblasts maintained in the presence of vitamin D. However, a larger proportion of positively stained cells was seen in the serum-free cultures. Fibroblasts cultured in serum-free medium without supplements exhibited only slight staining. The alkaline phosphatase staining patterns were consistent with the activity data. Cellular morphology was assessed by staining F-actin. Cells cultured in serumfree medium with vitamin $\mathrm{D}$ exhibited a more polygonal shape, similar in shape to osteoblastic cells. The fibroblasts cultured in serum-containing medium and in serum-free medium without additional additives maintained an elongated, spindle-shaped morphology, typical of fibroblasts.
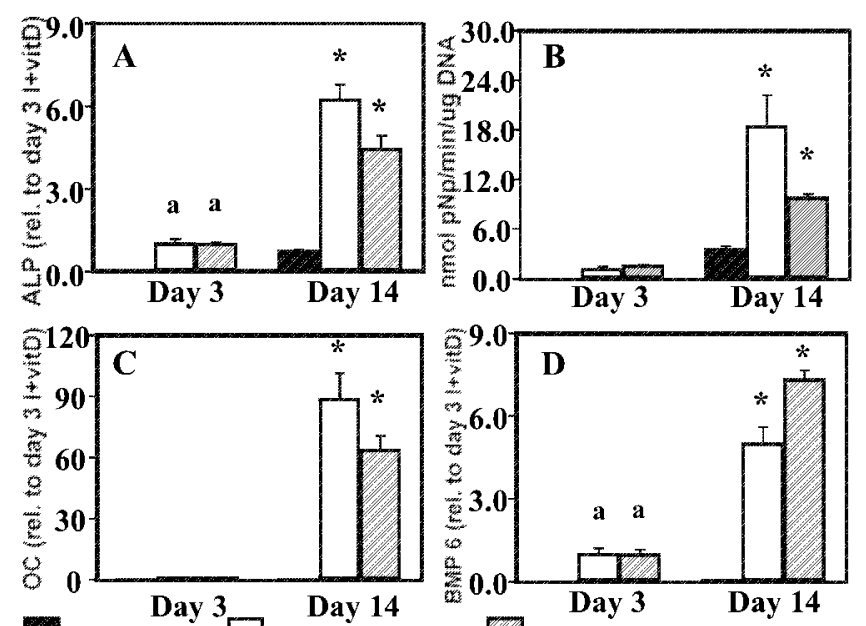

S Medium $\square$ I+vitD Medium I I+vitD+Noggin Medium

Fig. 2: (A) Alkaline phosphatase, (C) osteocalcin, and (D) BMP6 gene expression and (B) alkaline phosphatase activity of human dermal fibroblasts maintained in S, I+vitD, or I+vitD+Noggin medium. Gene expression is shown relative to day 3 samples cultured in $1+$ vitD medium. (a: $p<0.05$ compared to $S$ cultures, *: $p<0.05$ compared to all culture conditions)

3) BMP Signaling: Dermal fibroblasts cultured in monolayer and treated with noggin were analyzed at 3 and 14 days for alkaline phosphatase, osteocalcin, and BMP6 gene expression and alkaline phosphatase activity. Relative gene expression was normalized to GAPDH and expressed relative to the day $3 \mathrm{I}+\mathrm{vitD}$ samples. Alkaline phosphatase gene expression (Fig 2A) was significantly up-regulated in samples cultured with vitamin $\mathrm{D}$, with decreased expression when cultured in the presence of noggin. Control samples exhibited low levels of expression of alkaline phosphatase. Osteocalcin gene expression (Fig 2C) was only observed in samples cultured in the presence of vitamin D at 14 days.
Treatment with noggin caused a down-regulation of osteocalcin expression. BMP6 gene expression (Fig 2D) was also only seen in samples containing vitamin D. Treatment with noggin resulted in an increase in BMP6 gene expression.

Alkaline phosphatase activity normalized to DNA content (Fig 2B) was observed at low levels at the 3 day time point. At 14 days, alkaline phosphatase activity was detected in all cultures, with a significant increase in activity in cultures containing vitamin $\mathrm{D}$. Treatment with noggin resulted in a decrease in alkaline phosphatase activity by approximately $47 \%$.

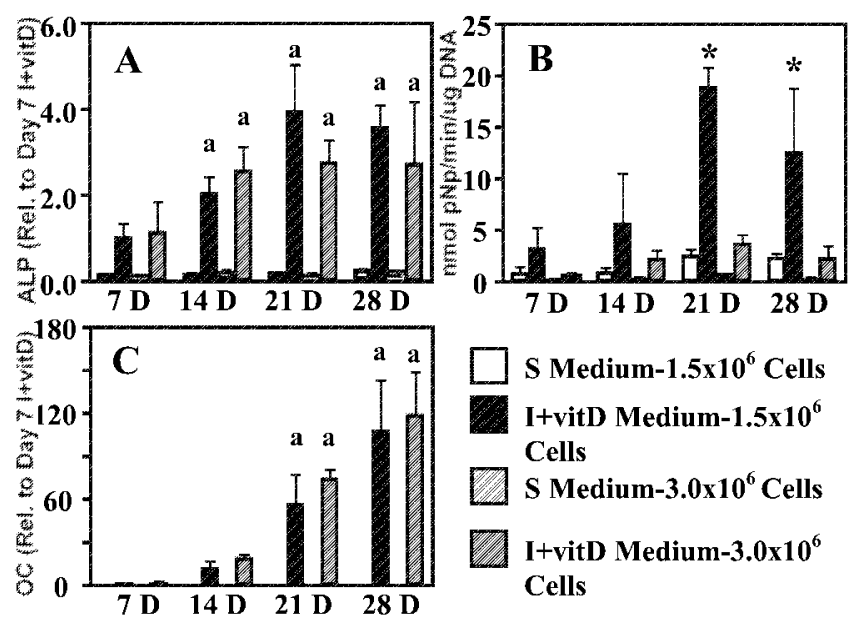

Fig. 3: (A) Alkaline phosphatase and (C) ostcocalcin gene expression and (B) alkaline phosphatase activity of fibroblast-seeded scaffolds initially seeded with 1.5 or $3.0 \times 10^{6}$ cells and maintained in $\mathrm{S}$ or $\mathrm{I}+\mathrm{vitD}$ medium. Gene expression is shown relative to day 7 samples cultured in $1+v i t D$ medium. (a: $p<0.05$ compared to $S$ cultures, *: $p<0.05$ compared to all culture conditions)

4) Three-Dimensional Culture Seeding Density: Analysis of 21 day samples seeded with initial densities of $0.5,1.5,3$, and $5 \times 10^{6}$ cells showed osteoblastic gene expression only in scaffolds cultured in I+vitD medium. Alkaline phosphatase gene expression (normalized to GAPDH) was approximately $40 \%$ higher in scaffolds seeded with 0.5 and 5.0 million cells compared to those seeded with 1.5 and 3 million cells, with no difference between 1.5 and 3 million cells. Osteocalcin gene expression did not differ significantly between seeding densities. Alkaline phosphatase activity was significantly elevated in scaffolds seeded with 1.5 million cells compared to all other groups. DNA content was significantly increased in the scaffolds seeded at higher initial seeding densities (1.5, 3, and 5.0), with a maximum of approximately 800,000 attached cells at initial seeding densities of 3 and 5 million cells/scaffold. Taking into account gene expression, alkaline phosphatase activity, and DNA content, seeding densities of 1.5 and 3 million cells were selected for further characterization.

Scaffolds seeded with 1.5 and $3 \times 10^{6}$ cells/scaffold were analyzed at 7, 14, 21, and 28 days. Alkaline phosphatase (Fig 3A) and osteocalcin (Fig 3C) gene expression were significantly higher in scaffolds cultured in I+vitD medium at all time points. There was no difference in gene 
expression between scaffolds initially seeded with 1.5 and $3.0 \times 10^{6}$ cells. Alkaline phosphatase activity (Fig 3B) was significantly increased in the scaffolds seeded at $1.5 \times 10^{6}$ cells/scaffold at the 21 and 28 day time points. Staining for alkaline phosphatase and osteocalcin supported the gene expression and activity results, with the most intense staining in the scaffolds seeded at the lower initial density.

\section{CONCLUSION}

These studies indicate that dermal fibroblasts cultured in chemically-defined medium supplemented with $1 \alpha, 25$ dihydroxyvitamin $\mathrm{D}_{3}$ are able to express gene and protein markers consistent with an osteoblastic phenotype. This process appears to be partially blocked by noggin, indicating a role of bone morphogenetic proteins in the osteoblastic differentiation of these cells. Further studies are necessary to elucidate the exact role of BMPs in this process. Taken together, these results demonstrate that the combination of dermal fibroblasts, $\beta$-tricalcium phosphate scaffolds, and 1 $\alpha, 25$-dihydroxyvitamin $\mathrm{D}_{3}$ has potential for use in bone tissue engineering applications.

\section{ACKNOWLEDGMENTS}

The authors would like to thank Orthovita for their generous gift of Vitoss scaffolds and Magdalena Jonikas and Robert Bowles for their assistance with experimental analysis

\section{REFERENCES}

[1] L.E. Weiss. Web Watch. Tissue Eng, 2002. 8(1): p. 167

[2] T. Boyce, J. Edwards, and N. Scarborough. Allograft bone. The influence of processing on safety and performance. Orthop Clin North Amer, 1999. 30(4): p. 571-81.

[3] R. Langer and J.P. Vacanti, Tissue Engineering. Science, 1993. 260: p. $920-926$.

[4] I. Notingher et al., In situ non-invasive spectral discrimination between bone cell phenotypes used in tissue engineering. J Cell Biochem, 2004. 92(6): p. 1180-1192.

[5] M. R. Urist. Bone: formation by autoinduction. Science, 1965. 150: p. 893-899.

[6] A. H. Reddi. and C. Huggins, Biochemical sequences in the transformation of normal fibroblasts in adolescent rats. Proc Nat Acad Sci, 1972. 69(6): p. 1601-1605.

[7] P. H. Krebsbach, et al., Gene therapy-directed osteogenesis: BMP-7transduced human fibroblasts form bone in vivo. Hum Gene Ther, 2000. 11: p. 1201-1210.

[8] R. B. Rutherford. et al., Bone morphogenetic protein-transduced human fibroblasts convert to osteoblasts and form bone in vivo. Tissue Eng, 2002. 8(3): p. 441-452.

[9] K. Hirata et al., Transplantation of skin fibroblasts expressing BMP-2 promotes bone repair more effectively than those expressing Runx2. Bone, 2003. 32(5): p. 502-512.

[10] C. Shui and A. Scutt, Mouse embryo-derived NIH3T3 fibroblasts adopt an osteoblast-like phenotype when treated with 1a,25dihydroxyvitamin $D_{3}$ and dexamethasone in vitro. J Cell Physiol, 2002. 193: p. 164-172.

[11] C. K. Hee, M.A. Jonikas, and S.B. Nicoll, Influence of threedimensional scaffold on the expression of osteogenic differentiation markers by human dermal fibroblasts. Biomaterials, 2006. 27(6): p. 875-884.
[12] Y. D. C. Halvorsen et al., Exiracellular matrix mineralization and osteoblast gene expression by human adipose tissue-derived stromal cells. Tissuc Eng, 2001. 7(6): p. 729-741.

[13] S. B. Nicoll et al., Modulation of proteoglycan and collagen profiles in human dermal fibroblasts by high density micromass culture and treatment with lactic acid suggests change to a chondrogenic phenotype. Conn Tiss Res, 2001. 42(1): p. 59-69.

[14] O. Frank et al., Real-time quantitative RT-PCR analysis of human bone marrow stromal cells during osteogenic differentiation in vitro. Journal of Cellular Biochemistry, 2002. 85(4): p. 737-746.

[15] V. L. Singer et al., Characterization of PicoGreen reagent and development of a fluorescence-based solution assav for doublestranded DNA quantitation. Anal Biochem, 1997. 249(2): p. 228-38. 